Research, part of a Special Feature on Integrating Indigenous Ecological Knowledge and Science in Natural Resource Management: Perspectives from Australia

\title{
Boundary Work: Engaging Knowledge Systems in Co-management of Feral Animals on Indigenous Lands
}

\author{
Catherine J. Robinson ${ }^{1}$ and Tabatha J. Wallington ${ }^{1}$
}

\begin{abstract}
The integration and use of Indigenous knowledge to inform contemporary environmental policy decisions and management solutions is a growing global phenomenon. However, there is little critical inquiry about how the interactions between scientific and Indigenous knowledge (IK) systems can be effectively negotiated for the joint management of socialecological systems. Such issues are urgent on Indigenous lands where co-management efforts respond to pressing conservation agendas and where the contribution of scientific knowledge and IK is required to better understand and manage complex socialecological systems. We draw on the notion of boundary work to examine how interaction at the boundaries of scientific and IK systems can be managed effectively as a contribution to co-management. The case study of feral animal co-management in Australia's Kakadu National Park illuminates the work required for local co-managers to bridge the divide between scientific and IK systems and to ensure the translation of knowledge for management decisions. Attributes of effective boundary work demonstrated in this case include: meaningful participation in agenda setting and joint knowledge production to enable comanagers to translate available knowledge into joint feral animal programs, Indigenous and non-Indigenous ranger efforts to broker interactions between knowledge systems that are supported by co-governance arrangements to ensure that boundary work remains accountable, and the production of collaboratively built boundary objects (e.g., feral animal impact assessment data) that helps to coordinate local action between co-managers. This case study illustrates the contribution of boundary work to local co-manager efforts to translate across knowledge systems and across the knowledge-action divide, even when consensus is difficult to achieve.
\end{abstract}

Key Words: co-benefits, co-managed boundary work, collaboration, environmental governance, feral animal management, Indigenous knowledge, knowledge-action systems

\section{INTRODUCTION}

In an era of rapid change, the complex character of socialecological systems (SES) has meant that the management of these systems is seen as both a technical and a governance challenge (Berkes 2009). Resilience theory seeks to define a quality of SESs that simultaneously captures their endurance and their capacity to adapt to change (Walker et al. 2006). Resilience thinking has been applied in considering how the design of governance systems, defined as the structures and processes by which people share power and make decisions, can enhance system attributes for resilience in different planning contexts, for example, natural resource management, and for different planning purposes (e.g., Folke 2004, Olsson et al. 2004).

The sharing of power and responsibility between the government and local resource users is at the core of comanagement, enabled through institutionalized arrangements for the active participation of resource users in making decisions (Berkes 2009). Co-management has emerged as a popular approach to environmental governance, particularly for enabling Indigenous communities to participate in environmental management decisions (Ross et al. 2009, Hill et al. 2012). Such participation can also involve different actors working together to make sense of knowledge from different sources or to generate new knowledge (Berkes 2009). These characteristics highlight that co-management is about managing relationships and handling different types of knowledge, as much as managing resources (Natcher et al. 2005).

Combining different kinds of knowledge such as science and local knowledge is recognized to be a difficult process (Goldstein 2010, Reid et al. in press). Yet the management of knowledge across Indigenous, scientific, and management domains is rarely addressed explicitly in the literature on comanagement (Berkes 2009), leaving open the question of how the integration of science and Indigenous knowledge is achieved through co-management in practice (Roux et al. 2006, Raymond et al. 2010). Research focused on the use of knowledge to support sustainable development has demonstrated that knowledge exchange across the boundaries of different domains of practice is not the apolitical, one-way transmission of knowledge as a product, implied by the linear notion of transfer (e.g., Jasanoff 1990). Jensen (2005) makes the point that only information can be shared, and that the acquisition of knowledge entails processes of learning, reframing, and understanding. In this process of negotiation, tensions arise at the interfaces between actors with different views of what constitutes reliable or useful knowledge; those 
tensions must be managed effectively if the potential benefits of knowledge are to be realized by society (Clark et al. 2010).

A growing body of research has emerged that analyzes boundaries and boundary work in knowledge-action systems (Gieryn 1983, Jasanoff 1990). Boundary work is defined as "those acts and structures that create, maintain, and break down boundaries" involving processes whereby legitimacy and cognitive authority are attached to knowledge (MacMynowski 2007:3). The concept of boundary work can assist in understanding and managing complex SESs, where the need to integrate different types of knowledge with differing logics and epistemologies is a significant challenge. The notion of boundary work provides a useful lens through which to investigate the relations between science and other forms of knowledge (Clark et al. 2010, Mollinga 2010), including Indigenous knowledge (IK; Reid et al. in press).

Here, we examine how interactions at the boundaries of scientific and IK systems can be managed effectively as a contribution to co-management. Our analysis contributes to the literature on knowledge systems and the role of boundary issues by taking as its point of departure the need for work at the boundary to negotiate interactions between different knowledge systems while maintaining the integrity of each knowledge system. Before describing the research context and methods, we introduce boundary work as a framework for addressing the challenges related to efforts to integrate knowledge and translate available knowledge into management decisions. Three elements of effective boundary work serve as an analytical framework to structure the analysis of co-management activities conducted by Indigenous and non-Indigenous rangers and Jawoyn Elders as co-managers of Kakadu National Park (KNP) in Australia. We conclude by highlighting the attributes and mechanisms of boundary work identified by co-managers as important to translate diverse forms of knowledge and action for the sustainable management of Indigenous lands.

\section{Integrating knowledge through boundary work}

Understanding the connection between knowledge and practice has led to growing research interest in how institutional structures and processes influence the use of different forms of knowledge for environmental planning purposes (Cash et al. 2003, Jacobs et al. in press). Scholars have recognized that while bridging Indigenous and sciencebased knowledge systems is both important and necessary, the difficulties involved should not be underestimated (Folke 2004, Berkes 2009). Case study evidence (Berkes et al. 2000, Kennett et al. 2004) points to a range of barriers to bridging different knowledge systems. Structural barriers include power differences (Brosius 2006), domination of decision making by governments (e.g., Davis 2006, Hill et al. 2012), as well as scientists' lack of respect for IK (Agrawal 2002, Gratani et al. 2011). Cognitive barriers have also been identified and include the absence of a common means of validating knowledge claims (Natcher et al. 2005) and the absence of a common language and a shared worldview (Bowman and Robinson 2002).

The integration of different knowledge systems and cultural values creates an opportunity for collaboration, but also a challenge (Wohling 2009). Standards of objectivity and repeatability underpin scientific knowledge practice and credibility (Jasanoff 1990). IK represents an Indigenous group's claim to authority over land and sea territory, which directs how and why knowledge is regarded, shared, and held (Folke 2004, Wohling 2009). The task of knowledge integration is therefore one of situated engagement, "a means of approaching interactions in which engagement between people has to occur in situated places ... and concepts and practices become reliant on situated circumstances for their relevance and meaning" (Howitt and Suchet-Pearson 2006:332).

Conceiving of knowledge as generated in social processes of interaction between different stakeholders represents a move away from a focus on knowledge types such as local and scientific knowledge (e.g., Gagnon and Berteaux 2009) toward an action-oriented view of knowledge centered on ways of knowing that are bound up in practices of resource management and use (Nygren 1999, Lejano and Ingram 2009). This active perspective on knowledge informs the growing literature on the co-production of knowledge, which understands knowledge as a process of relating that involves negotiation of meaning among partners (e.g., Bäckstrand 2003, Roux et al. 2006). While knowledge transfer models view knowledge as a product and focus on the efficiency or effectiveness of moving knowledge between one domain and another, the co-production perspective focuses on the quality of institutionalized social relationships (Wynne 2001). The arrangements that underpin the achievement of knowledge integration through co-production practices have been examined in theories of boundary work (Gieryn 1983).

Gieryn (1983) originally introduced the notion of boundary work to describe the way scientists demarcate science from other knowledge systems such as religion or politics to gain credibility, legitimacy, and epistemic authority for scientific knowledge and practice in the public sphere. Although Gieryn emphasizes that boundaries are created and managed to separate and exclude less favored science or non-science, it has also been noted that boundaries can serve as interfaces that facilitate knowledge exchange, bridging, inclusion, and coproduction (Star 2010). As Halffman (2003) emphasizes, boundary work involves a process of "defining a practice in contrast with other practices, to protect it from unwanted participants and interference, while trying to ascribe proper ways of behavior for participants and non-participants (demarcation); simultaneously boundary-work defines proper 
ways for interaction between these practices and makes such an interaction possible and conceivable (co-ordination)" (Halffman 2003:27).

Based on Halffman's (2003) account, co-ordination and cooperation can occur without the need to resolve culturally situated differences (Goldstein 2010) and without the need for prior consensus (Star and Griesemer 1989). The quality of institutionalized relationships is a key condition for the successful facilitation of knowledge engagement, mediation, and exchange. Studies have confirmed the importance of this condition, demonstrating that the most successful boundary work practices are collaborative and involve two-way communication between actors on both sides of the boundary (Lemos and Morehouse 2005). Communication relies on iterative and inclusive processes to enable other values to be involved in knowledge sharing and co-production. Translation is necessary because knowledge often has jargon or presumptions that are difficult to understand or may be contested. Mediation is critical to manage tradeoffs between salient, credible, or legitimate attributes of knowledge contributions (Lejano and Ingram 2009, Jacobs et al. in press). An important role in this interaction is played by boundary agents, defined as people or organizations that act as intermediaries between organizations or sectors to identify information needs, problem definitions, and possible solutions by communicating and building relationships across the boundary between social worlds (Roux et al. 2006, Goldstein 2010). Boundary organizations, as originally described by Cash and Moser (2000) to facilitate two-way translation between the domains of science and policy, are similar to bridging organizations (Hahn et al. 2006). Bridging organizations are identified as critical to the efforts of combining complementary knowledge, skills, and capacities of different actors (Berkes 2009) and facilitating knowledge translation (Olsson et al. 2004).

The role of boundary-spanning individuals was identified as more important than that of boundary organizations in several cases (McNie et al. 2008, Reid et al. in press). Facilitation of knowledge integration by boundary agents relies on an awareness of what is involved that can only be generated through participation in the process of knowledge production (Nowotny et al. 2001), highlighting the important role of researchers as facilitators of boundary work (Brosius 2006). Boundary work is also carried out through the co-production of boundary objects (Star and Griesemer 1989). Boundary objects are artifacts of boundary work, for example, classifications, maps, and standardized methods, which serve as translators and mediators between different social worlds while embodying the knowledge of the people who create them (e.g., Eden 2009, Goldman 2009). The co-production of boundary objects acts as a means of translation, maintaining enough features in common to provide a basis for coordinated action while also being subject to multiple interpretations (Star and Griesemer 1989, Star 2010). Importantly, the integrity of each knowledge system and the respective responsibilities of individuals are maintained in this process, contributing to the authority and utility of boundary objects for action by different groups (Star and Griesemer 1989).

Both boundary work theory and co-management research are based on the assumption that knowledge is generated in the particular context of application as a situated process of translation and co-production (Berkes 2009, Ross et al 2009). A situated perspective on knowledge also provides the focus for building SES resilience through an emphasis on social aspects of knowledge practices and the use of IK to interpret and respond to feedbacks from the environment (Berkes et al. 2000, 2003, Howitt and Suchet-Pearson 2006). This situated perspective on knowledge recognizes that knowledge integration is achieved through the engaged work of boundary agents and the co-production of boundary objects that maintain the integrity of different knowledge systems and accountabilities, are meaningful to stakeholders, and can establish a robust basis for joint management action.

While boundaries can serve useful functions, for example, to maintain the integrity of scientific knowledge, boundaries can also act as barriers to collaboration. As such, management of these boundaries is considered paramount to knowledge integration for management action (Jacobs et al. in press). This is particularly important in cross-cultural settings where attention to the institutional conditions that enable different knowledge systems to be integrated and validated for effective environmental decision making is critical (Gratani et al. 2011).

From this body of research, three key attributes of effective boundary work have been identified: (1) meaningful participation in agenda setting and joint knowledge production by stakeholders on both sides of the boundary; (2) governance arrangements that ensure boundary work is accountable to stakeholders on both sides of the boundary; and (3) the coproduction of boundary objects. We use these attributes as an analytical framework with which to examine the work required to bridge the divide between Indigenous and scientific knowledge systems for the co-management of feral animals in KNP.

\section{KAKADU NATIONAL PARK}

Co-management is now a common planning model for the management of protected areas across Australia (Ross et al. 2009). KNP is a World Heritage Area that was one of the first co-management arrangements negotiated in Australia when Indigenous Traditional Owners gained formal legal ownership of large areas under the Aboriginal Land Rights (Northern Territory) Act of 1976. This land claim was achieved as part of a package designed to satisfy several interests in the region, including mining, tourism, and conservation. Indigenous land rights were granted on the condition that the area would be 
leased back to the Commonwealth Government for 99 yrs. Management of KNP is through a multi-tiered partnership between Indigenous landowners, the park director, and a board of management on which the former two are both represented (Lawrence 2000). Under this agreement, park managers have an obligation to promote "Aboriginal administration, management, and control of the Park," as well as to use "traditional skills and knowledge to manage the Park," and to encourage "Indigenous business and enterprise" (Australian Government 2007).

Feral animals such as horses (Equus caballus), pigs (Sus scrofa), and water buffalo (Bubalus bubalis) have been present in the Kakadu region since their introduction into the Northern Territory by British colonizers in the mid-1800s (Robinson et al. 2005). Scientific research conducted into the effects of feral animal populations on the ecology of the Kakadu region has shown the damage that feral animals cause to the physical structure of soils and habitats and the ways in which feral animals compete and displace native species (Bayliss and Yeomans 1989, Robinson and Whitehead 2003, Woinarski et al. 2007). Local Indigenous people have seen and reacted to feral animals in different ways in response to their historical interactions with other animals, including those now deemed feral, people's access to traditional territories, and the effects these animals have had on Indigenous peoples' customary economic activities (Berkes et al. 2000). As a result, some feral animals are important food sources, others such as horses are loved as bush pets, and some feral animals such as pigs are considered a threat to Indigenous lands (Robinson et al. 2005).

The decision-making approach and techniques used to cull feral animal species in KNP have historically been a source of conflict between Indigenous elders, Indigenous KNP rangers, and non-Indigenous KNP rangers. Aerial shooting, which has been the method of choice for feral management in many parts of the park, is politically contentious (Robinson and Whitehead 2003). At the time of our research, the Indigenous elders we consulted were concerned about the wasteful nature of mass animal slaughter, its effects on Indigenous people's ability to create revenue from the sale of meat products derived from the culls, and a preference from Indigenous elders to enable paying tourists to undertake safari hunting activities. The current Kadadu management plan emphasizes the park's value as a living cultural landscape and commits co-managers to manage landscapes that have been influenced by Indigenous land management regimes for thousands of years. However, the extent to which park managers are obliged to maintain park values that reflect contemporary Indigenous interactions and adaptations to the presence of feral animals is not clear.

\section{METHODS}

This research was conducted as part of a broader project commissioned by the Kakadu Board to investigate Indigenous ecological knowledge and aspirations relating to feral animal management in the region (Robinson et al. 2005). Project design and fieldwork involved interviews and workshops with Jawoyn and non-Indigenous rangers and senior Jawoyn Traditional Owners (or Jawoyn elders) in a two-stage process.

\section{Linking knowledge about feral animal impacts to feral animal management action}

The first phase of the feral impact assessment involved interviews with Elders and rangers to understand the IK base and value sets associated with different species in the park. Workshops at each of the park ranger stations then engaged Jawoyn rangers, non-Indigenous rangers, and elders in a process of mapping, explaining, and prioritizing (as low, medium, and high) the need for programs to manage the positive and negative effects of feral animals within different regions of the park. These perspectives were collated to create a park-scale map to identify where high levels of consensus existed (on areas of high priority in relation to negative feral animal impacts), and where high levels of disagreement remained about priorities and impacts and about the knowledge and action required to co-manage feral pigs, horses, and buffalo in KNP. These maps were checked and refined through discussions held at each ranger station, presented to senior park managers, and then submitted for agreement to the Kakadu board of management. This process led to Board approval of a pilot co-management project in low to medium conflict areas in the southern part of the park (Jawoyn Traditional Owner territories).

\section{Developing boundary mechanisms to facilitate co- management of feral pigs in Jawoyn territories}

Rangers working in the southern region of the park agreed to begin by addressing issues that had achieved the greatest consensus, in this case, perceptions regarding the negative impacts of pigs. Agreement between Jawoyn elders, Jawoyn rangers, and non-Indigenous rangers was reached on the design of the pilot project, and six Jawoyn elders were chosen by the local Jawoyn community to be involved in the feral control pilot project and to guide the co-management process.

A workshop was held that led to an agreement between Jawoyn elders and rangers on the location for the pilot project and the design of the proposed pig culling operation. The opportunities for Indigenous enterprise (e.g., to allow hunting safaris, sell horses, and sub-contract pet meat operations) were discussed. Consensus was finally achieved to conduct a ground-based shooting operation that would enable trained Jawoyn rangers to participate and report back and to provide meat to the Jawoyn community, followed by an aerial shoot to cull sufficient numbers. Three habitat types at two sites that required management attention were also negotiated. The habitat types were represented by: (1) two waterholes that were identified to be significant cultural and food harvesting sites for Jawoyn residents and that were being heavily used by resident feral animal populations, (2) savanna woodlands 
Table 1. Effects of feral pigs on different values identified by Jawoyn elders and rangers through the walking narrative assessment.

\begin{tabular}{ll}
\hline \hline Values & Impacts \\
\hline Source of food (i.e., small populations need & $\begin{array}{l}\text { Pigs provide a food source for local Jawoyn people. Feral animals such as pigs do not have the same strict } \\
\text { harvesting and distribution protocols as do native animals hunted in Jawoyn territories, which makes pigs a } \\
\text { to be maintained in some areas) }\end{array}$ \\
$\begin{array}{l}\text { desirable food source for Jawoyn hunters who are uncertain about protocols required for specific species or } \\
\text { places or who wish to minimize conflict when sharing meat with family and community members. }\end{array}$
\end{tabular}

Source of income (i.e., there is a desire to retain substantial numbers of pigs in some areas for commercial opportunities)

Tourism (tourists enjoy seeing pigs, but some tourist sites are very damaged by wallows)

Impacts on specific species and places
A few Indigenous people are employed in pig control activities or wish to pursue this as an employment opportunity. Some income is generated from Indigenous participation in commercial hunting or harvesting ventures.
There have been positive reports from tourists about pig sightings on roads in savanna woodlands; these can lead to denied requests for permission to pursue recreational pig hunting. There have also been negative reports from tourists about pig sign and sightings because of concern about environmental and aesthetic impacts.

Feral pigs reduce the abundance of native yam and freshwater turtle in waterholes and swamps, which are valued food sources. Pig wallows silt up waterholes and create erosion gullys in riverine habitats. There is concern about the spread of weeds caused by pigs moving through the savanna. There is high concern that local disturbance at a local sacred site near one waterhole would cause catastrophic consequences to sites and resources that connect this sacred site to other ecological and sacred features and resources in Jawoyn territories. where large numbers of feral animals had been seen, and (3) Melaleuca riparian swamps where feral animal tracts were causing significant gully erosion.

Two assessment methods were facilitated as part of research efforts to support the co-management project: transect mapping, and a walking narrative assessment to obtain the local, practical knowledge of Jawoyn rangers and elders. The first method drew on the approach used by Edwards et al. (2000) and involved mapping three transects in each habitat type and surveying four plots in each transect. Several variables were measured in each plot, including age of tracks, percent coverage, and rooting disturbance. The second, parallel method involved an on-ground monitoring exercise. A walking narrative approach was adopted that involved recording the observations and perspectives of Jawoyn rangers and elders at each of the sites before and after feral control operations. Recorded interviews were transcribed and coded into themes using Filemaker Pro qualitative data analysis software. Extracts from interviews are presented in italics to help contextualize them.

Data from the plot analyses and summaries of the walking narrative assessments were presented and discussed with rangers and Jawoyn elders in workshops held before and after the agreed feral animal control operation was completed. Workshop discussions focused on the effectiveness of assessment mechanisms developed through this research to inform and evaluate co-management decisions. Participants' perspectives on the methods and techniques used to inform assessments of feral management in the pilot project are presented next.

\section{RESULTS: MECHANISMS TO FACILITATE CO- MANAGED BOUNDARY WORK}

Workshop discussions and on-ground walking narrative assessments revealed the multiple values and impacts Jawoyn people associated with pigs (Table 1). Jawoyn Elders and rangers involved in the assessments noted that pigs were valued as a source of food and income (i.e., through employment in pig control activities) and were enjoyed by some tourists, but did cause significant damage to specific species and places.

The density and age of pig tracks and evidence of pig rooting and wallows recorded to inform the scientific assessment of feral pig impacts highlighted the different scales and intensity of feral pig populations and impacts. Intense impacts (> 75\% of survey plots covered in tracks, roots, and wallows) were recorded at waterholes, whereas smaller and dispersed populations and impacts were recorded at sites in the savanna woodland $(<25 \%$ of survey plots covered in tracks, roots, and wallows). The technical impact assessments also provided a refined analysis of pig damage by demonstrating that old tracks can linger for some time in the landscape, making it difficult to assess visually the efficacy of the control program through on-ground monitoring alone.

Both data sets generated from the assessment process were analyzed by rangers and Jawoyn elders and included the identification of a range of mechanisms that were useful to comanage efforts to enable different knowledge contributions to interact and inform management decisions. These mechanisms included: (1) enabling Jawoyn and nonIndigenous rangers to broker knowledge/action links; (2) 
respect and use of tacit knowledge and interactional expertise, that is, expertise in mediating between the certified knowledge of science and the uncertified, experience-based knowledge and issue-meanings held by Indigenous people (after Wynne 2002), to develop purpose-built knowledge partnerships that could inform particular management activities; and (3) the use of collaborative boundary objects.

\section{Brokering knowledge/action links}

Rangers acted as boundary agents to broker knowledge/action links in this complex boundary work dynamic; all rangers identified this role as a challenge to manage effectively. One non-Indigenous ranger who had extensive experience working in KNP reflected on how this brokering role affected his willingness and ability to enable knowledge to be shared or received:

\section{Joint management in Kakadu can be bloody frustrating to put into practice ... we have so many meetings that just don't seem to lead to anywhere ... sometimes I get so frustrated I just go out and shoot a few pigs to feel like something is being done!}

Maintaining the integrity of knowledge systems was also a critical and careful component of co-managed boundary work as Jawoyn rangers considered the contributions of senior Jawoyn elders. This involved respect for the authority of Jawoyn rules used to govern IK contributions and the judgment to combine this with scientific studies and their own knowledge and experience of feral animal impacts in the park. The practical knowledge offered by both Jawoyn and nonIndigenous rangers highlighted why on-ground shooting that employed Jawoyn rangers could provide multiple outcomes, including employment benefits for Indigenous communities. As one Jawoyn ranger put it, on-ground shoots also provided a chance to "work together to care for country" to build relationships and new ways of knowing about this dynamic landscape. Scientific studies conducted on feral animal impacts and effective culling techniques in the Kakadu region were also shared and helped explain why on-ground shooting often focused on large animals that were easier to shoot, and that aerial culls were required to create significant reduction in pig populations (e.g., Bayliss and Yeomans 1989).

\section{Interactional expertise}

The interactional expertise of co-managers to support the ongoing co-operation of all stakeholders in the process was critical, as one Ranger aptly put it, "to work out how to work with each knowledge contribution." Key to this was the development of new knowledge:

It is critical that this assessment is linked to our work here [in the park].... to make an explicit link between our judgment about damage caused by pigs with management priorities and efforts. ... At the end of the day [co-management] is about working together
... this ain't easy - there is a lot of conflict [about other management issues] that can cloud our efforts ... It really does require us all to build our capabilities to develop ... I guess you could call it purpose-built knowledge ... to guide our work.

On-ground monitoring and regular meetings between rangers and Elders provided a means for co-managers to handle different knowledge contributions about assessment and control methods. In this process, Jawoyn elders emphasized that what constitutes real change and improved management practice could not be based solely on environmental and economic criteria. As one Jawoyn elder noted, "a waterhole is not just a waterhole but a place in our country," highlighting the legitimacy of place-based assessments. From Jawoyn perspectives, the waterhole at one site was a significant place where pigs had caused regional-scale impacts because significant cultural and spiritual ties connected this waterhole to other sacred sites in the landscape. As one Jawoyn elder explained:

\section{You know the concern [and resources and interest] in the park when an animal is endangered? Well the same attention needs to be paid to here ... if this place becomes too dirty we won't come here to hunt, fish, bring family, share stories about this place - and if this happens for too long ... the place will die ... our country will die.}

\section{Collaborative boundary objects}

In the co-management planning domain, joint site assessments, joint mapping, and workshops acted as boundary objects to facilitate the communication and translation of knowledge across Indigenous and non-IK systems. In the Jawoyn domain, repeated walks through country and the articulation of relationships between kin and country in this process were essential to enable the Jawoyn community to evaluate the quality of Jawoyn knowledge about feral animals and their effects.

Broad-scale maps indicating levels of agreement between different assessments of feral animal impacts helped to generate a consensus vision on impacts caused by a given species for a given site and type and intensity of feral management operations for particular areas and species. An example of a map generated for the co-management of pigs in the park at the time this research was conducted acted as a boundary object to refine the discussion about where and why there was divergence or consensus between assessments of feral animal impacts for some areas and species (Fig. 1). This process enabled available knowledge to be tested and validated and supports the findings of Gratani et al. (2011), who found that evaluation of IK involving Indigenous knowledge holders is important to reinforce Indigenous people's confidence in their own knowledge via a negotiated process of its acceptance by other collaborators. 
Fig. 1. Map of collaborative knowledge to inform pig management options in Kakadu National Park, 2005.

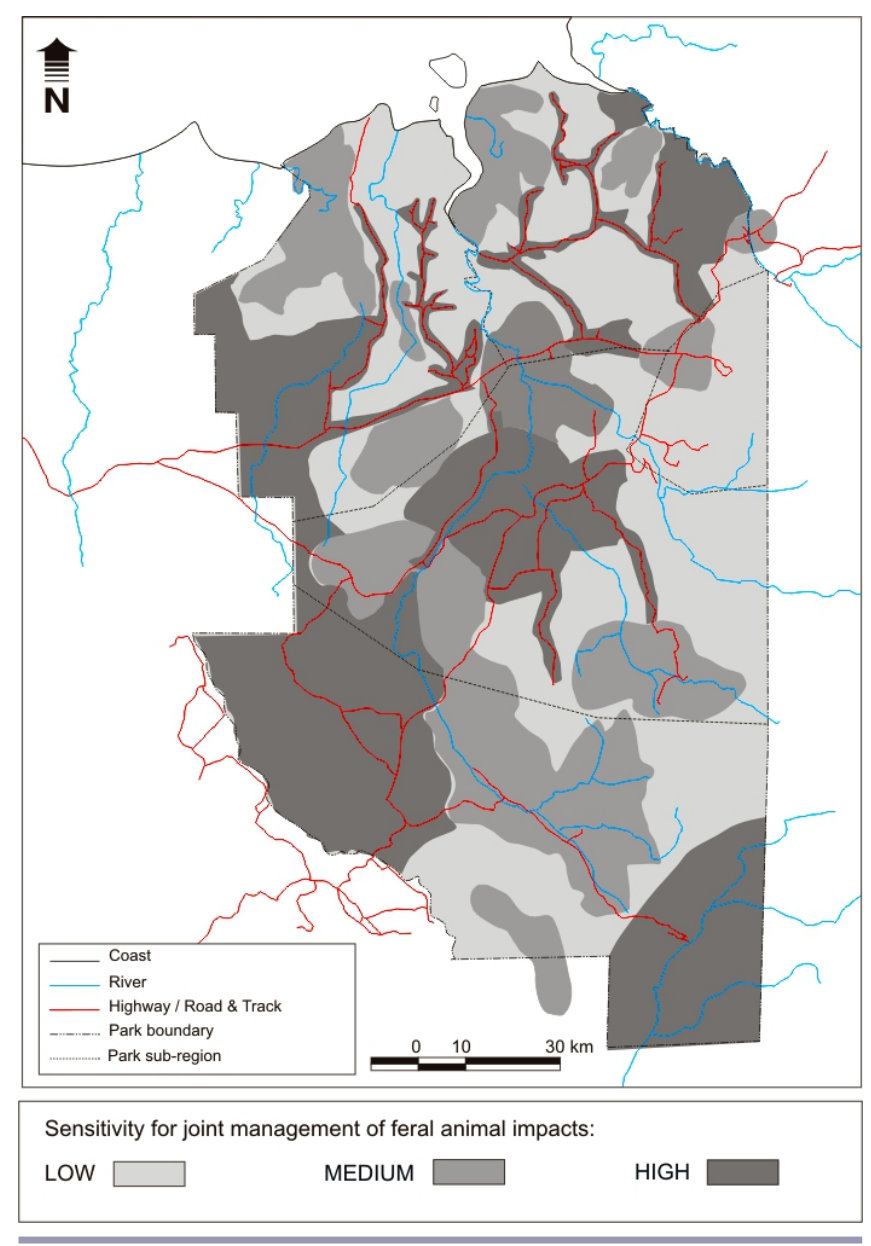

Repeated Indigenous visits to country offered through the walking narrative approach became another critical mechanism to enable additional IK contributions to be tested and refined. On one such visit, two senior Jawoyn elders asked to make a detour to a nearby historic buffalo site. The elders shared buffalo and horse histories and emphasized the value these species held for Jawoyn's livelihoods. At the end of the day, one Jawoyn elder reflected on the multiple balancing efforts that had to be negotiated within and between knowledge contributions:

It's important you know, sharing our stories about this land - buffalo, horse - they were here before them tourists arrived-before the park-they belong as well. ... I reckon that helicopter story told by [the Jawoyn ranger] is also important. ... I didn't know that numbers were coming up and damaging stony country - we need to ensure [that other Jawoyn elders] hear that story as well. ... It's important to support [the rangers] for what they are doing - it's a hard job you know - balancing all the ideas all the time. ... We should do a small [on-ground feral control operation] shoot that employs us mob and also lets the park do their work to protect that important waterhole.

As this summary of the day's discussion highlights, such visits to country offer a vital mechanism for boundary work in the Indigenous domain. The use of IK for decision making was done through a process of community decision making, based on the assumption that outcomes may require future review. Repeated visits to country combined with the key role of Indigenous rangers as brokers ensured that Jawoyn input and knowledge was appropriate for the feral animal management context, place, or purpose.

\section{DISCUSSION}

We examined the question of knowledge integration in the context of a joint assessment of feral animal impacts by Indigenous and non-Indigenous rangers and Jawoyn elders in KNP. The knowledge systems engaged in the habitat transect mapping resulted in a quantification of impacts to facilitate comparison across habitat types and over time. The qualitative expression of IK through stories and narratives resulted in the articulation of Indigenous standards and relationships associated with pigs and their management.

The attributes of co-managed boundary work highlighted here closely parallel the principles of successful boundary work derived from a comparative analysis of integrated natural resource management programs in the United States (Clark et al. 2010). Key attributes of effective boundary work outlined in the Introduction structure the Discussion:

- Meaningful participation in agenda setting and joint knowledge production by stakeholders from both sides of the boundary. Visits to country, on-ground monitoring, and workshops enabled the integration of a range of knowledge to inform management actions. A key issue here was to ensure that the agenda was not captured by either Indigenous values or scientific values, especially in the early stages of study design.

- Governance arrangements that ensure boundary work is accountable to stakeholders on both sides of the boundary. These goals were achieved and involved Indigenous and non-Indigenous rangers and Jawoyn elders in the on-ground monitoring exercise.

- The production of collaboratively built boundary objects. Maps and impact assessment data helped generate the commitment of Indigenous and non-Indigenous participants to management action oriented to feral animal impacts. The discussion and debate generated by these boundary objects assisted all parties to gain clarity about the nature of, and reasons for, different 
participants' focus on particular impacts, places, and species.

Our research highlights that all three attributes of effective boundary work relied on the work of rangers as boundary agents to facilitate the process of co-producing knowledge for co-management action. At the same time, these boundary agents felt the tensions involved in working across the boundary of different knowledge domains. Frustration expressed by rangers highlights that communication is required to build boundary objects and that participation in agenda setting must be problem focused. This required comanagers to engage with the issue of what each knowledge contribution actually represents, as well as with the practicalities of incorporating a range of valid contributions into formal decision-making processes (Lejano and Ingram 2009).

Co-managers in KNP and other similar management environments must make decisions and take actions despite high levels of uncertainty associated with both the knowledge contributions and the efficacy of management responses (Izac and O'Brien 1991, Berkes 2009). Uncertainty often provides a key motivation for boundary work efforts, and critical boundary work efforts are required to handle the inherent biases and limitations in any knowledge or management contribution. This boundary work often involves complex processes of assessments regarding what constitutes credible knowledge, real change, and improved management practice. Such judgments cannot be based on criteria that collaborative partners have no opportunity to test. Rather, ongoing negotiation is required to select the knowledge used to judge the performance of collaboration, to judge the process used to undertake this assessment, and to determine what can be learned from past experience.

A key challenge to innovative brokering and consensusbuilding efforts in KNP has been an ongoing struggle to get the broader park planning and policy authorities to support local co-management activities and initiatives. Many Jawoyn interviewees expressed a concern, which they believed to be widespread, about the continuing challenges Indigenous people face in their efforts to enter into equitable comanagement arrangements. In KNP, a response to this challenge could include ongoing support for knowledge partnerships that are not based on the assumption that IK is only relevant for "traditional" problems such as providing input into historical fire management practices (Wohling 2009). Instead, boundary work mechanisms need to be devised and resourced that enable holders of IK to use, test, and integrate their knowledge with other types of knowledge to address "non-traditional" issues such as the management of feral animal impacts on Indigenous lands.

The challenge of achieving equitable and enduring comanagement also highlights the need for knowledge partnerships to be supported and aligned to decision-making units that operate at multiple scales (Olsson et al. 2004). Resource limitations meant that local mechanisms devised to produce and communicate fit-for-purpose knowledge relating to the management of feral animals impacts could no longer be funded after our research was completed. Subsequent changes to government agency staff in the park challenged onground efforts to build on what has been learned from past experience to guide subsequent culling operations. Indigenous elders in KNP still recall and worry about the serious social, cultural, and livelihood impacts of context-insensitive feral animal culling programs that have occurred in this region (Robinson and Whitehead 2003). The need for comanagement approaches and relationships to overcome a history of conflict and build the resilience of this unique SES based on recognition of the rights of Indigenous land owners continues to be demonstrated forcibly.

\section{CONCLUSION}

Analysis of the ways in which knowledge was used and tested to guide feral animal control operations in KNP highlights the challenges faced by co-managers when handling different knowledge contributions, particularly when there is conflict. A key source of such conflict had been the process of translating knowledge across the boundary between Indigenous and non-IK systems. Our work makes it clear that to understand the integration of science and IK, attention must be paid to the role of rangers as boundary agents in considering and combining different representations of feral animals and their impacts to inform joint feral animal management decisions.

Our research supports other studies that show that the institutional landscape needs to be considered as carefully as the ecological system to identify the features that contribute to the resilience of the SES (Berkes et al. 2003, Plummer and Armitage 2007). This has prompted growing research interest in aspects of governance systems that are robust to change, including the creation of new knowledge systems. We argue that co-managed governance systems that involve Indigenous people require knowledge partnership and boundary work capabilities to enable different knowledge contributions and interactions to underpin co-management agreements and activities on Indigenous lands.

In the face of issues associated with feral animals on Indigenous land in a World Heritage Area, an innovative knowledge co-production system was created through a local and purpose-built knowledge partnership. The case of feral animal co-management in this northern Australian region illuminates the work required to bridge the divide between scientific and IK systems in co-management, including collaboration between domains to produce boundary objects that act to coordinate local action between domains when consensus is difficult to achieve. In KNP, as elsewhere, efforts 
to build effective and long-term knowledge partnerships to undertake such boundary work is an aspiration that is still being worked toward, rather than something that has already been achieved. Established policies and procedures limit the formal institutional capacity for innovation and for supporting co-management efforts (Olsson et al. 2004), and knowledge production occurs amid the history of prior agreements and the social and technical work these policies represent (Nadasdy 2003, Goldstein 2010). This historical legacy can act to constrain boundary work because new solutions displace the negotiated social arrangement as well as the technical work embodied in the on-stage, authoritative voice of these established institutions (Jasanoff 1990). In such situations, boundary agents can assist knowledge communities by working backstage to create new safe spaces where partners can come together to create joint outputs and reach agreement on new rules of engagement that are supportive of innovation and creativity (Goldstein 2010, Reid et al. in press).

A key challenge to Indigenous co-management efforts is to ensure that Indigenous people and their unique knowledge contributions are integral to the ongoing negotiation of comanagement agendas and arrangements. Such knowledge partnerships need to enable local people to use and refine their knowledge systems in ways that maintain the integrity of knowledge practices as well as provide conservation and Indigenous benefits. Integral to such knowledge partnerships is a requirement that collaborators engage in ongoing coboundary work to build the trust and interactional expertise needed to test and co-produce knowledge that is meaningful, relevant, and robust enough to maintain co-operation for sustainable joint management action.

Responses to this article can be read online at:

http://www.ecologyandsociety.org/vol17/iss2/art16/

responses/

\section{Acknowledgments:}

We thank the Indigenous Traditional Owners and Park Rangers of Kakadu National Park and acknowledge Mat and Alexander Gilfedder, who both assisted in the fieldwork. Thanks also to the contributions offered to the broader Kakadu project by Peter Whitehead, Dermot Smyth, and Brett Ottley. We also thank Ro Hill and the special editors whose comments vastly improved this paper.

\section{LITERATURE CITED}

Agrawal, A. 2002. Indigenous knowledge and the politics of classification. International Social Science Journal 54 (3):287-297. http://dx.doi.org/10.1111/1468-2451.00382

Australian Government. 2007. Kakadu National Park Management Plan 2007-2014. Australian Government
Printing Service, Canberra, Australia. [online] URL: http://w ww.environment.gov.au/parks/publications/kakadu/pubs/managementplan.pdf.

Bäckstrand, K. 2003. Civic science for sustainability: reframing the role of experts, policy-makers and citizens in environmental governance. Global Environmental Politics 3 (4):24-41. http://dx.doi.org/10.1162/152638003322757916

Bayliss, P., and K. M. Yeomans. 1989. The distribution and abundance of feral livestock in the top end of the Northern Territory (1985-86), and their relation to population control. Australian Wildlife Research 16(6):651-676. http://dx.doi.org /10.1071/WR9890651

Berkes, F. 2009. Evolution of co-management: role of knowledge generation, bridging organizations and social learning. Journal of Environmental Management 90 (5):1692-1702. http://dx.doi.org/10.1016/j.jenvman.2008.12.001

Berkes, F., J. Colding, and C. Folke. 2000. Rediscovery of traditional ecological knowledge as adaptive management. Ecological Applications 10(5):1251-1262. http://dx.doi.org/1 0.1890/1051-0761(2000)010[1251:ROTEKA]2.0.CO;2

Berkes, F., J. Colding, and C. Folke, editors. 2003. Navigating social-ecological systems: building resilience for complexity and change. Cambridge University Press, Cambridge, UK.

Bowman, D. M. J. S., and C. J. Robinson. 2002. The Getting of the Nganabbarru: observations and reflections on Aboriginal buffalo hunting in northern Australia. Australian Geographer 33(2):191-206. http://dx.doi.org/10.1080/000491 $\underline{80220151007}$

Brosius, J. P. 2006. What counts as local knowledge in global environmental assessments and conventions? Pages 129-144 in W. V. Reid, F. Berkes, T. J. Wilbanks, and D. Capistrano, editors. Bridging scales and knowledge systems: concepts and applications in ecosystem assessment. Island Press, Washington, D.C., USA.

Cash, D. W., W. C. Clark, F. Alcock, N. M. Dickson, N. Eckley, D. H. Guston, J. Jager, and R. B. Mitchell. 2003. Knowledge systems for sustainable development. Proceedings of the National Academy of Sciences 100(14):8086-8091. htt p://dx.doi.org/10.1073/pnas.1231332100

Cash, D. W., and S. C. Moser. 2000. Linking global and local scales: designing dynamic assessment and management processes. Global Environmental Change 10(2):109-120. htt p://dx.doi.org/10.1016/S0959-3780(00)00017-0

Clark, W. C., T. P. Tomich, M. van Noordwijk, N. M. Dickson, D. Catacutan, D. Guston, and E. McNie. 2010. Toward a general theory of boundary work: insights from the CGIAR's natural resource management programs. CID Working Paper 199. Centre for International Development, Harvard 
University, Cambridge, Massachusetts, USA. [online] URL: http://www.hks.harvard.edu/centers/cid/publications/facultyworking-papers/cid-working-paper-no.-199. http://dx.doi.org /10.2139/ssrn.1676287

Davis, M. 2006. Bridging the gap or crossing a bridge? Indigenous knowledge and the language of law and policy. Pages 145-164 in W. V. Reid, F. Berkes, T. J. Wilbanks, and D. Capistrano, editors. Bridging scales and knowledge systems: concepts and applications in ecosystem assessment. Island Press, Washington, D.C., USA.

Eden, S. 2009. The work of environmental governance networks: traceability, credibility and certification by the Forest Stewardship Council. Geoforum 40(3):383-394. http:// dx.doi.org/10.1016/j.geoforum.2008.01.001

Edwards, G. P., N. D. de Preu, B. J. Shakeshaft, and I. V. Crealy. 2000. An evaluation of two methods of assessing feral cat and dingo abundance in central Australia. Wildlife Research 27(2):143-149. http://dx.doi.org/10.1071/WR98067

Folke, C. 2004. Traditional knowledge in social-ecological systems. Ecology and Society 9(3): 7. [online] http://www.ec ologyandsociety.org/vol9/iss3/art7/.

Gagnon, C. A., and D. Berteaux. 2009. Integrating traditional ecological knowledge and ecological science: a question of scale. Ecology and Society 14(2): 19. [online] URL: http://w ww.ecologyandsociety.org/vol14/iss2/art19/.

Gieryn, T. F. 1983. Boundary-work and the demarcation of science from non-science: strains and interests in professional ideologies of scientists. American Sociological Review 48 (6):781-795. http://dx.doi.org/10.2307/2095325

Goldman, M. 2009. Constructing connectivity: conservation corridors and conservation politics in East African rangelands. Annals of the Association of American Geographers 99 (2):335-359. http://dx.doi.org/10.1080/00045600802708325

Goldstein, B. E. 2010. Epistemic mediation: aligning expertise across boundaries within an endangered species habitat conservation plan. Planning Theory and Practice 11 (4):523-547. http://dx.doi.org/10.1080/14649357.2010.525374

Gratani, M., J. R. A. Butler, F. Royee, P. Valentine, D. Burrows, W. I. Canendo, and A. S. Anderson. 2011. Is validation of indigenous ecological knowledge a disrespectful process? A case study of traditional fishing poisons and invasive fish management from the Wet Tropics, Australia. Ecology and Society 16(3): 25. http://dx.doi.org/10.5751/ES$\underline{04249-160325}$

Hahn, T., P. Olsson, C. Folke, and K. Johansson. 2006. Trustbuilding, knowledge generation and organizational innovations: the role of a bridging organization for adaptive comanagement of a wetland landscape around Kristianstad, Sweden. Human Ecology 34(4):573-592. http://dx.doi.org/10 $.1007 / \mathrm{s} 10745-006-9035-\mathrm{Z}$

Halffman, W. 2003. Boundaries of regulatory science: eco/ toxicology and aquatic hazards of chemicals in the US, England, and the Netherlands, 1970-1995. Dissertation. University of Amsterdam, Amsterdam, The Netherlands.

Hill, R., C. Grant, M. George, C. J. Robinson, S. Jackson, and N. Abel. 2012. A typology of indigenous engagement in Australian environmental management: implications for knowledge integration and social-ecological system sustainability. Ecology and Society 17(1): 23. http://dx.doi.or g/10.5751/ES-04587-170123

Howitt, R., and S. Suchet-Pearson. 2006. Rethinking the building blocks: ontological pluralism and the idea of 'management.' Geografiska Annaler Series B: Human Geography 88(3):323-335. http://dx.doi.org/10.1111/j.1468-0 459.2006.00225.X

Izac, A.-M. N., and P. O'Brien. 1991. Conflict, uncertainty and risk in feral pig management: the Australian approach. Journal of Environmental Management 32(1):1-18. http://dx. doi.org/10.1016/S0301-4797(05)80077-5

Jacobs, K., L. Lebel, J. Buizer, L. Adams, P. Matson, E. McCullough, P. Garden, G. Saliba, and T. Finan. In press. Linking knowledge with action in the pursuit of sustainable water-resources management. Proceedings of the National Academy of Sciences, in press. http://dx.doi.org/10.1073/pnas .0813125107

Jasanoff, S. 1990. The fifth branch: science advisers as policymakers. Harvard University Press, Cambridge, Massachusetts, USA.

Jensen, P. E. 2005. A contextual theory of learning and the learning organization. Knowledge and Process Management 12(1):53-64. http://dx.doi.org/10.1002/kpm.217

Kennett, R., C. J. Robinson, I. Kiessling, D. Yunupingu, Munungurritj, and D. Yunupingu. 2004. Indigenous initiatives for co-management of Miyapunu/sea turtle. Ecological Management and Restoration 5(3):159-166. http://dx.doi.org /10.1111/j.1442-8903.2004.00204.x

Lawrence, D. 2000. Kakadu: the making of a national park. Melbourne University Press, Melbourne, Australia.

Lejano, R. P., and H. Ingram. 2009. Collaborative networks and new ways of knowing. Environmental Science and Policy 12(6):653-662. http://dx.doi.org/10.1016/j.envsci.2008.09.005

Lemos, M. C., and B. J. Morehouse. 2005. The co-production of science and policy in integrated climate assessments. 
Global Environmental Change 15(1):57-68. http://dx.doi.org /10.1016/j.gloenvcha.2004.09.004

MacMynowski, D. P. 2007. Pausing at the brink of interdisciplinarity: power and knowledge at the meeting of social and biophysical science. Ecology and Society 12(1): 20. [online] URL: http://www.ecologyandsociety.org/vol12/iss1/ art20\%.

McNie, E. C., M. van Noordwijk, W. C. Clark, N. M. Dickson, N. Sakuntaladewi, Suyanto, L. Joshi, B. Leimona, K. Hairiah, and N. Khususiyah. 2008. Boundary organizations, objects and agents: linking knowledge with action in agroforestry watersheds. Joint CID Graduate Student and Research Fellow Working Paper 34 and World Agroforestry Centre-ICRAF Working Paper 80. Centre for International Development at Harvard University, Cambridge, Massachusetts and World Agroforestry Centre, Nairobi, Kenya. [online] URL: http://w ww.cid.harvard.edu/cidwp/grad/034.html.

Mollinga, P. P. 2010. Boundary work and the complexity of natural resources management. Crop Science 50(2):S1-S9.

Nadasdy, P. 2003. Hunters and bureaucrats: power, knowledge, and aboriginal-state relations in the southwest Yukon. UBC Press, Vancouver, Canada.

Natcher, D. C., S. Davis, and C. G. Hickey. 2005. Comanagement: managing relationships, not resources. Human Organization 64(3):240-250.

Nowotny, H., P. Scott, and M. Gibbons. 2001. Re-thinking science: knowledge and the public in an age of uncertainty. Polity Press, London, UK.

Nygren, A. 1999. Local knowledge in the environmentdevelopment discourse: from dichotomies to situated knowledges. Critique of Anthropology 19(3):267-288. http:// dx.doi.org/10.1177/0308275X9901900304

Olsson, P., C. Folke, and F. Berkes. 2004. Adaptive comanagement for building resilience in social-ecological systems. Environmental Management 34(1):75-90. http://dx.d oi.org/10.1007/s00267-003-0101-7

Plummer, R., and D. Armitage. 2007. A resilience-based framework for evaluating adaptive co-management: linking ecology, economics and society in a complex world. Ecological Economics 61(1):62-74. http://dx.doi.org/10.1016/ j.ecolecon.2006.09.025

Raymond, C. M., I. Fazey, M. S. Reed, L. C. Stringer, G. M. Robinson, and A. C. Evely. 2010. Integrating local and scientific knowledge for environmental management. Journal of Environmental Management 91(8):1766-1777. http://dx.do i.org/10.1016/j.jenvman.2010.03.023

Reid, R. S., D. Nkedianye, M. Y. Said, D. Kaelo, M. Neselle, O. Makui, L. Onetu, S. Kiruswa, N. Ole Kamuaro, P.
Kristjanson, J. Ogutu, S. B. BurnSilver, M. J. Goldman, R. B. Boone, K. A. Galvin, N. M. Dickson, and W. C. Clark. In press. Evolution of models to support community and policy action with science: balancing pastoral livelihoods and wildlife conservation in savannas of East Africa. Proceedings of the National Academy of Sciences, in press. http://dx.doi.o rg/10.1073/pnas.0900313106

Robinson, C. J., D. Smyth, and P. J. Whitehead. 2005. Bush tucker, bush pets, and bush threats: cooperative management of feral animals in Australia's Kakadu National Park. Conservation Biology 19(5):1385-1391. http://dx.doi.org/10. $\underline{1111 / \mathrm{j} .1523-1739.2005 .00196 . \mathrm{x}}$

Robinson, C. J., and P. Whitehead. 2003. Cross-cultural management of pest animal damage: a case study of feral buffalo control in Australia's Kakadu National Park. Environmental Management 32(4):445-458. http://dx.doi.org $\underline{10.1007 / \mathrm{s} 00267-003-0013-6}$

Ross, H., C. Grant, C. J. Robinson, A. Izurieta, D. Smyth, and P. Rist. 2009. Co-management and Indigenous protected areas in Australia: achievements and ways forward. Australasian Journal of Environmental Management 16(4):242-252. http:/ /dx.doi.org/10.1080/14486563.2009.9725240

Roux, D. J., K. H. Rogers, H. C. Biggs, P. J. Ashton, and A. Sergeant. 2006. Bridging the science-management divide: moving from unidirectional knowledge transfer to knowledge interfacing and sharing. Ecology and Society 11(1): 4. [online] URL: http://www.ecologyandsociety.org/vol11/iss1/art4/.

Star, S. L. 2010. This is not a boundary object: reflections on the origin of a concept. Science, Technology and Human Values 35(5):601-617. http://dx.doi.org/10.1177/0162243910 $\underline{377624}$

Star, S. L., and J. R. Griesemer. 1989. Institutional ecology, 'translations' and boundary objects: amateurs and professionals in Berkeley's Museum of Vertebrae Zoology, 1907-39. Social Studies of Science 19(3):387-420. http://dx.d oi.org/10.1177/030631289019003001

Walker, B. H., L. H. Gunderson, A. P. Kinzig, C. Folke, S. R. Carpenter, and L. Schultz. 2006. A handful of heuristics and some propositions for understanding resilience in socialecological systems. Ecology and Society 11(1): 13.[online] URL: http://www.ecologyandsociety.org/vol11/iss1/art13/.

Wohling, M. 2009. The problem of scale in indigenous knowledge: a perspective from northern Australia. Ecology and Society 14(1): 1. [online] URL: http://www.ecologyands ociety.org/vol14/iss1/art1/.

Woinarski, J., B. Mackey, H. Nix, and B. Trail. 2007. The nature of northern Australia: natural values, ecological processes and future prospects. ANU E Press, Canberra, Australia. 
Wynne, B. 2001. Creating public alienation: expert cultures of risk and ethics on GMOs. Science as Culture 10(4):445-481. http://dx.doi.org/10.1080/09505430120093586

Wynne, B. 2002. Seasick on the Third Wave? Subverting the hegemony of propositionalism: response to Collins \& Evans (2002). Social Studies of Science 33(3):401-417. http://dx.doi. org/10.1177/03063127030333005 